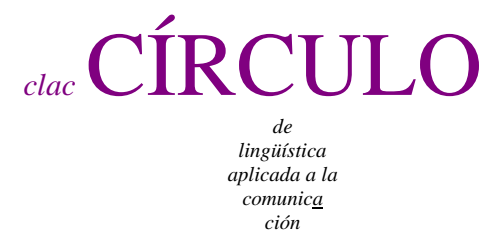

$55 / 2013$

\title{
CARACTERIZACIÓN LINGÜÍSTICA DEL TIPO DE TEXTO: \\ EL DISCURSO ELECTORAL COMO EJEMPLO
}

\author{
Eladio Duque \\ Doctorado de Comunicación Social Universidad Complutense de Madrid \\ eladio duque gomez en ucm es
}

\section{Resumen}

Este artículo se concentra en el estudio de la principal característica lingüística de los géneros o tipos de texto, la estructura textual. Se propone una estructura textual que complementa la secuencia de las etapas (cf. Eggins y Martin, 1997) con las posiciones jerárquicas y las relaciones semánticas que mantienen dichas etapas entre sí. El estudio de esta estructura se aborda mediante la combinación de los análisis de movimientos (cf. Swales, 1990; Upton y Connor, 2009) con las teorías sobre las relaciones de coherencia (cf. Mann y Thompson 1988; Wolf y Gibson, 2006). El análisis parte del modelo de unidades propuesto por Garrido (2007) e identifica las unidades mediante los cambios en los patrones de cohesión. El enfoque propuesto se ilustra con el caso de un discurso electoral.

Palabras clave: Tipos de texto, género, estructura textual, discurso electoral

Duque, Eladio. 2013.

Caracterización lingüística del tipo de texto: el discurso electoral como ejemplo.

Círculo de Lingüística Aplicada a la Comunicación 55, 9-39.

http://www.ucm.es/info/circulo/no55/duque.pdf http://revistas.ucm.es/index.php/CLAC DOI http://dx.doi.org/10.5209/rev_CLAC.2013.v55.43264

(C)2013 Eladio Duque Gómez

Círculo de Lingüística Aplicada a la Comunicación (clac)

Universidad Complutense de Madrid. ISSN 1576-4737. http://www.ucm.es/info/circulo 


\begin{abstract}
Linguistic characterization of text types: the electoral campaign speech as an example This article focuses on the main linguistic feature of the text types or genres: the textual structure. We propose a textual structure that supplements the sequence of stages (cf. Eggins and Martin, 1887) with the hierarchical organization and the semantic relations maintained between stages. The proposed approach to this structure combines move analysis (cf. Swales, 1990; Upton and Connor, 2009) with theories of coherence relations (cf. Mann and Thompson, 1988; Wolf y Gibson, 2006). The analysis adopts the model of supra-sentential units articulated by Garrido (2007); those units are identified through the changes in patterns of cohesion. Our approach is illustrated with an election campaign speech.
\end{abstract}

Key words: Text type, genre, textual structure, election campaign speech

Índice

1. Introducción 11

2. Texto y discurso 12

3. Discursos y patrones de cohesión 13

4. Tipo de texto y estructura textual 14

5. Análisis de movimientos 15

6. Relaciones de coherencia 16

7. Estructura textual del discurso electoral 17

8. Análisis de un discurso electoral 20

8.1. Método 20

8.2. Segmentación textual: identificación de los discursos 22

8.3. Relaciones entre discursos 27

9. Conclusiones 32

Bibliografía 35 


\section{Introducción}

Las expresiones ‘tipo de texto’, 'género’, 'registro’ y 'estilo’ forman parte del enredo terminológico que remite a las variedades de la lengua relacionadas con las diferentes situaciones, acciones e intenciones comunicativas. Los términos género y tipo de texto suelen vincularse a un concepto más cercano. Su objeto lingüístico de estudio es el mensaje como una unidad estructural, con principio y final. En la distribución del estudio del discurso que propone Cortés (2012a), podemos ubicar este objeto lingüístico en el 'plano secuencial', aquel que atiende al 'discurso en su compleción'. Por el contrario, el objeto lingüístico habitualmente relacionado con estilo y registro son las características transversales y locales que no atienden al texto como totalidad estructural, y que se ubican en los planos enunciativo e intraenunciativo.

En definitiva, los géneros y tipos de texto definen las situaciones e intenciones comunicativas mediante características lingüísticas que dependen de textos completos. Una excepción a esta generalización, porque se predica de tipos de secuencias de oraciones, es el concepto de tipo de texto popularizado por Adam (1992). El tipo de texto de Adam ha tenido gran aceptación en el estudio del texto en español (cf. Calsamiglia y Tusón, 2007 o Calvi, 2010; entre otros); los autores que utilizan este concepto, reservan el término género para considerar textos completos. Vistos desde esta perspectiva, los tipos de texto equivalen a las tradicionales categorías retóricas de la narración, descripción, argumentación y exposición. Estas categorías retóricas reciben otras denominaciones que amplían el mencionado enredo terminológico; por ejemplo, Werlich (1975) habla de bases textuales, Bassols y Torrent (1997) de modelos textuales, Smith (2003) de modos del discurso o Steen (1999) de tipos de discurso.

Otra distinción clásica entre tipo de texto y género la propone Biber (1988), quien considera el término género vinculado a la tradición de la crítica literaria y de la retórica y el término tipo de texto, a la lingüística. Desde su punto de vista -el que seguimos en este artículo-, tipos de textos y géneros remiten al mismo fenómeno. La diferencia está en que el tipo de texto se define por las características lingüísticas, 'criterio interno' al propio texto, y el género por 'criterios externos', como el tipo de audiencia o de hablante, de actividad, de propósito o la situación comunicativa. Volviendo a la distribución del estudio del discurso de Cortés (2012a), los géneros se definen a partir de los 'condicionantes' o 'variación externa' y los tipos de texto a partir de las 
'realizaciones’ o ‘variación interna’.

Una vez aclarada la vinculación del tipo de texto con la lingüística y con textos completos, en este artículo nos centramos en el estudio de su principal característica, la estructura textual. Para ello, en el próximo apartado proponemos el marco de unidades desde el que se analiza dicha estructura. El apartado 3, ‘discurso y patrones de cohesión’ propone elementos para la detección de las unidades propuestas. El apartado 4, 'tipo de texto y estructura textual' profundiza en las características de la estructura que define a un tipo de texto. El apartado 5, 'análisis de movimientos', describe como los análisis de movimientos atienden a dos de las características necesarias para definir la estructura textual: la identificación de los componentes de dicha estructura y su orden de aparición. El apartado 6, 'relaciones de coherencia', presenta como las teorías sobre las relaciones de coherencia atienden a otras dos características que completan el estudio de la estructura textual: las relaciones entre los componentes y su organización jerárquica. El apartado 7, 'estructura textual del discurso electoral' presenta la estructura textual del discurso electoral atendiendo a las cuatro características tratadas en los apartados anteriores. Por último, el apartado 8 ilustra en un discurso electoral la estructura del tipo de texto propuesta.

\section{Texto y discurso}

Otro enredo terminológico es el que afecta a texto y discurso. Tanto es así, que desde hace décadas, la aclaración entre estos términos es una de las preocupaciones compartidas por los capítulos introductorios de manuales y estudios generales de lingüística textual y análisis del discurso (véase, por ejemplo, van Dijk, 1977: 3). En el estudio preliminar de la edición española de Beaugrande y Dressler (1997), Sebastián Bonilla advierte de la unanimidad en el desacuerdo terminológico. La situación sigue siendo parecida, como indica Alba-Juez (2009: 6 y ss.), quien sigue a Schiffrin (1994) en la elección del contexto como el criterio para diferenciar texto y discurso. Desde este punto de vista, el habitual desde la perspectiva pragmática -según aprecia Portolés (2004: 107)-, el texto más el contexto equivale al discurso; y el discurso menos el contexto, al texto.

En este artículo, los términos texto y discurso remiten a las unidades lingüísticas supraoracionales definidas por Garrido (2007). El texto es la unidad lingüística superior 
constituida por discursos organizados según las pautas estipuladas por los tipos de textos. Por eso, los textos son siempre de un tipo determinado. En este modelo de unidades, los discursos están constituidos por oraciones conectadas. Así, los discursos son unidades intermedias, entre el texto y la oración. Equivalen a los pasajes de Smith (2003) o a los segmentos de discurso de Asher y Lascarides (2003), ya que también se definen en términos de oraciones estructuradas. Otras unidades semejantes -aunque definidas en otros términos- son las unidades secuenciales temáticas e ilocutivas de Cortés (2012a) o el párrafo en definiciones como las de Longracre (1979) o Fuentes (1993).

El salto de la oración al texto, sin pasar por el discurso, obliga a conceder al texto las propiedades fundamentales del discurso: la cohesión y la coherencia (cf. Garrido, 1997: 214 y ss.). La cohesión y la coherencia se presentan sin necesidad de considerar el texto en su conjunto. Desde los primeros estudios de la cohesión (cf. Halliday y Hasan, 1976) se adjudica al texto estas propiedades. Ocurre así porque se entiende el texto como la superación del ámbito oracional. Por ello, con frecuencia los estudios sobre la cohesión se ejemplifican con fragmentos de textos. Los fragmentos seleccionados siempre presentan cierta unidad, las anáforas están resueltas y todas las oraciones relacionadas entre sí, compartiendo un contexto común. Son fragmentos cohesivos y coherentes. Estos fragmentos son unidades de discurso, o simplemente discursos.

\section{Discursos y patrones de cohesión}

Ya que el texto se compone de discursos y los discursos se caracterizan por las propiedades de la cohesión y la coherencia, cada texto puede segmentarse en discursos atendiendo a la continuidad y cambio de los elementos cohesivos. La denominada coherencia referencial, de entidad o continuidad tópica (cf. Garnham et al., 1982; Givón, 1983 o Sanders et al., 2001) se construye manteniendo la referencia en torno a unas mismas entidades, centrales en el ‘tema discursivo’ (cf. Hidalgo Downing 2003). Adicionalmente, la coherencia referencial también se construye mediante la continuidad de la referencia temporal, aspectual y modal (cf. Givón 1995). La continuidad temporal se consigue por la repetición de elementos textuales, como adverbios y tiempos verbales, que activan el mismo marco temporal. Por su parte, la continuidad temática tiene su expresión sintáctica en los patrones de cohesión. El final de un patrón en torno 
a un referente y el inicio de otro marca una frontera entre dos discursos. Los patrones de cohesión son conjuntos de elementos textuales que mantienen relaciones de cohesión. Por ejemplo, las denominadas cadenas correferenciales, cadenas anafóricas o cadenas nominales están formadas por elementos léxicos que mantienen entre sí relaciones de identidad.

En este artículo utilizaremos el término cadena correferencial y las definimos como un conjunto de elementos léxicos que activan el mismo referente. Así, además de las repeticiones y anáforas que mantienen las mencionadas relaciones de identidad, consideramos otros elementos como las anáforas de los posesivos que también activan el referente articulador de la cadena. En definitiva, los elementos de las cadenas correferenciales son anáforas léxicas y gramaticales. Las anáforas gramaticales se valen de pronombres, de posesivos y de morfemas verbales de persona. El uso de las proformas indica que las entidades a las que se refieren son más centrales, salientes o en las que está el foco del segmento textual (cf. Ariel, 1994 o Prince, 1981, entre otros). Las anáforas léxicas, entendidas en un sentido amplio, se expresan con la repetición, ciertos adjetivos relacionales, sinónimos, hiperónimos e hipónimos acompañados por ciertos complementos o cualquier otra expresión con la que se active el mismo referente.

\section{Tipo de texto y estructura textual}

Desde el punto de vista de la situación de comunicación el tipo de texto suele definirse a partir de la finalidad de la acción. Visto a la inversa, como hace Garrido (1997: 228) 'en lugar de considerarlo por servir para cierta finalidad, cada tipo de texto se puede analizar según la manera -lingüística- en que la cumple’. De acuerdo con Eggins y Martin (1997: 343), la principal manera lingüística de expresar la finalidad es la estructura textual; en sus términos, 'el reflejo lingüístico más importante de las diferencias de propósito es la estructura de las etapas mediante la cual se despliega el texto’. Hasan (1984) también privilegia la estructura textual en el análisis de los géneros. Propone la 'estructura potencial genérica' como aquella que define a un tipo de texto incluyendo sus posibilidades de variación estructural. Asimismo, la influyente propuesta de Swales (1990) analiza los géneros mediante una estructura textual constituida por movimientos textuales; donde cada movimiento se define por su 
contenido y función en el texto. En textos concretos, los componentes de la estructura sean denominados movimientos, etapas o secciones- son segmentos textuales compuestos por conjuntos de oraciones; es decir, discursos.

La estructura textual que expresa la finalidad debe adaptarse, en primer lugar e inevitablemente, a las condiciones de transmisión, 'el texto organiza los discursos según el modo de transmisión, principalmente en cuanto a quién interviene y cuánto tiempo lo hace’ (Garrido, 2009: 233). La estructura textual que proponen Swales y Eggins y Martin y es de tipo secuencial; queda definida por dos características: la identificación y caracterización de cada componente y su orden de aparición. En este artículo proponemos otras dos características que completan la descripción de la estructura: las relaciones que mantienen los componentes entre sí y su organización jerárquica. La combinación de la perspectiva del análisis de movimientos y la de las teorías de las relaciones de coherencia cubre las cuatro características propuestas.

\section{Análisis de movimientos}

Cada componente de la estructura textual, cada discurso, puede identificarse y caracterizarse mediante la exigencia de un contenido determinado. Estos requisitos semánticos no son globales, no se define el tipo de texto por el tema tratado. Vistos así, los tipos de texto se definen por la organización de unidades discretas que, en un grado apropiado de abstracción, sí tienen ciertas restricciones semánticas. Un enfoque tradicional de la estructura textual que atiende a exigencias locales de contenido es el estudio del relato, para el que Labov (1972) propone una estructura de cuatro secciones. De hecho, aunque van Dijk (1983) define las superestructuras como estructuras formales, aclara que las superestructuras narrativas (como las del relato) se basan en mayor medida en el sistema semántico, frente a las superestructuras argumentativas cuyas bases son puramente formales.

Los análisis de movimientos de Swales o de etapas de Eggins y Martin extienden a todo tipo de textos, no solo narrativos, esta perspectiva de análisis. En estos análisis, cada componente de la estructura se define mediante un titular como 'presentación del nicho de estudio' (en las introducciones de los artículos científicos) o ‘introducción de los personajes, lugar y tiempo del relato’. Por esta razón, Paltridge (1994: 295) señala que 'Hasan, Bhatia y Swales recurren a categorías basadas en el contenido para determinar 
la estructura de género, más que en el modo en que dicho contenido se expresa lingüísticamente’. Como solución, Scott y Tribble (2006: 109 y ss.), Biber et al. (2007) o Upton y Connor (2009) definen cada movimiento por sus rasgos léxico-gramaticales frecuentes. Vistos de este modo, cada movimiento puede definirse por la presencia de determinados rasgos lingüísticos y de elementos léxicos que comparten características semánticas.

En este artículo, definimos cada discurso de la estructura textual a partir de los referentes en torno a los que se despliegan los patrones de cohesión. Los requisitos semánticos que definen cada discurso de la estructura del tipo de texto son una abstracción de las características de estos referentes, de modo que sean compartidas por todos los textos de ese tipo.

\section{Relaciones de coherencia}

Los análisis de movimientos identifican los componentes de la estructura textual y describen su orden de aparición. Las teorías sobre las relaciones de coherencia (cf. Mann y Thompson, 1988; Asher y Lascarides, 2003 o Renkema, 2009, entre otros) permiten describir las relaciones de significado que mantienen los componentes entre sí y la jerarquía textual. Del mismo modo que el estudio tradicional del relato es el ejemplo clásico de descripción del tipo de texto mediante la identificación de unidades por sus requisitos semánticos o substantivos, el estudio de la argumentación es el ejemplo clásico de descripción del tipo de texto por requisitos formales o relacionales. Todas las propuestas de estructura de la argumentación comparten al menos dos componentes: a) las razones, premisas, hipótesis o argumentos y b) la opinión, conclusión o tesis. Las estructuras argumentativas no solo afectan al nivel textual de organización de discursos -por ejemplo un anuncio publicitario-, sino también en el nivel discursivo de relaciones entre oraciones, que ilustra el ejemplo 1.

(1) Marta suspendió. Miguel se enfadó

En el ejemplo, la primera oración es la razón de la segunda, la conclusión. Las relaciones que establecen las estructuras argumentativas son relaciones de tipo causal (cf. Duque, en prensa), donde las premisas son las causas y la conclusión el efecto o resultado; de ahí que la introducción del marcador de discurso causal no altere la 
representación semántica: 'Miguel se enfadó porque Marta suspendió'. Desde la perspectiva de las relaciones de coherencia, la identificación de los componentes es un epifenómeno de la identificación de la relación. Dicho de otro modo, los componentes se definen a partir de la relación, criterio formal frente al substantivo de los requisitos semánticos: el suspenso de Marta es entendido como razón gracias a la construcción conjunta con la conclusión, el enfado de Miguel.

Además del tipo de conexión semántica, algunas teorías de las relaciones de coherencia, como la Teoría de la Estructura Retórica (Mann y Thompson, 1988), incluyen la jerarquía entre los componentes en la definición de cada relación. En el ejemplo anterior, las oraciones mantienen una relación de Causa, donde el componente de la relación que es causa ocupa una posición jerárquica inferior respecto al componente que es efecto o resultado. Las relaciones de coherencia que hemos ilustrado con oraciones suceden también en el ámbito textual, relacionado discursos entre sí.

$\mathrm{Al}$ igual que las relaciones entre oraciones, las relaciones entre unidades de discurso pueden comprobarse por la introducción de los marcadores de discurso asociados al tipo concreto de relación (estrategia seguida, entre otros, por Wolf y Gibson, 2006).

\section{Estructura textual del discurso electoral}

En cuanto a las condiciones de transmisión, los discursos políticos son exposiciones orales monologales; pertenecen al ‘macrogénero de la alocución’ (cf. Camacho, 2007). La principal repercusión lingüística de estas condiciones en la estructura del tipo de texto es que las primeras y últimas unidades discursivas se centran en la situación de enunciación. En cuanto a las condiciones de la acción social, la acción donde se incluyen los discursos políticos tiene una finalidad persuasiva. La principal repercusión lingüística de estas condiciones en la estructura textual son las relaciones causales argumentativas que afectan a todo el texto. La combinación de estos dos condicionantes -la transmisión oral monológica y la finalidad argumentativa- resultan en una estructura textual caracterizada por una exposición oral en la que hay incrustada o solapada una estructura argumentativa. Junto al discurso de despedida propio de la exposición oral- se introduce la conclusión de la argumentación. Junto a la primera unidad de discurso de saludos, se anuncia el contenido del resto del texto. La unidad inicial mantiene una relación de coherencia de elaboración con el resto del texto; la conclusión, mantiene relaciones causales con los discursos intermedios. 
Otra de las características de la transmisión, que la recepción completa del texto sea obligatoria, repercute en la jerarquía de la estructura textual. Los tipos de texto que el lector puede abandonar antes de llegar al final se materializan en una estructura textual piramidal, como la descrita por van Dijk (1988) para la noticia. Por el contrario, en tipos de textos como los discursos políticos, donde la recepción completa es la norma, la parte final habitualmente contiene información fundamental y se sitúa en la posición más alta de la jerarquía textual. En el caso del discurso político en la última posición privilegiada se sitúa la conclusión de la argumentación. La figura 1 presenta la estructura textual descrita hasta el momento.

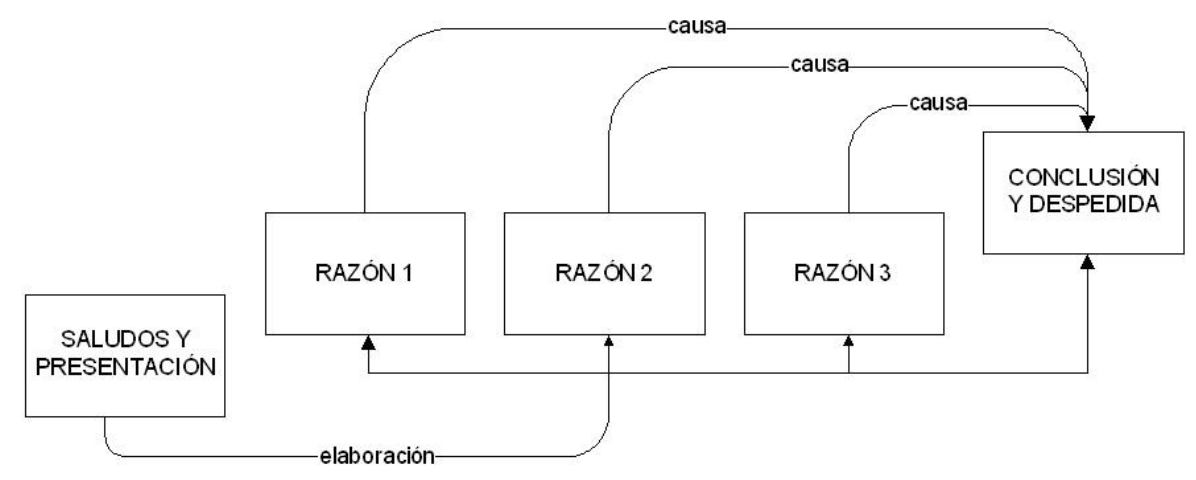

Figura 1. Relaciones de coherencia y jerarquía de la estructura textual del discurso político

El modelo de estructura textual propuesto es más detallado que la trimembre introducción, cuerpo del discurso y cierre- basada en la tradición retórica (cf. Reisigl, 2008 o Vilches et al., 2007). Cortés (2011) parte de esta estructura -que denomina ilocutivo-textual-, y la complementa con unidades temáticas. En nuestra propuesta el valor ilocutivo lo aportan las relaciones que mantienen entre si los componentes; equivale a los efectos retóricos que dan nombre a la teoría de Mann y Thompson. Con todo y como se habrá advertido, la estructura propuesta sigue resultando demasiado general como para caracterizar a un tipo de texto tan concreto como los discursos electorales. Los requisitos semánticos locales de cada componente de la estructura permiten esta caracterización específica.

Las unidades de inicio y cierre, propias de la presentación oral, se caracterizan por la alta densidad de deícticos. Parte de estos deícticos participan en un procedimiento catafórico que remite al resto del texto, categorizando su contenido o finalidad (v. g. 'Hoy he venido aquí para hablarles de’). Estos procedimientos catafóricos que caracterizan las primeras unidades discursivas de los discursos políticos forman parte de 
un tipo de expresiones metadiscursivas especializadas en la organización textual (cf. Thompson, 2003). Estos procedimientos catafóricos -similares a los ‘temas de adelanto’ que propone Cortés (2013)- son los responsables de la construcción de la relación de elaboración de los discursos iniciales con el resto del texto. En el discurso final, además de la alta densidad de deícticos, se introduce la conclusión de la argumentación. La conclusión de la argumentación de los diferentes tipos de discursos políticos activa un referente que es característico de cada tipo específico de discurso político. Por ejemplo, en el discurso electoral se trata de la presentación de un escenario electoral futuro.

Los discursos intermedios -las razones- también presentan requisitos específicos para cada tipo de discurso político. En la estructura textual del discurso electoral los discursos intermedios se caracterizan porque están articulados por la referencia central a los participantes, construida mediante cadenas correferenciales. Por ejemplo, un discurso se define por la referencia destacada al partido de la oradora y el siguiente discurso por los adversarios políticos. De este modo, el texto progresa por el cambio en el valor en la categoría referencial de los participantes. En Duque (2009), ya advertimos como un discurso en un foro, acogido como un discurso electoral, se caracterizaba por la estructura textual definida por la construcción de los diferentes participantes.

Los cinco tipos de participantes en los discursos políticos dependen de la acción social de la que este tipo de texto forma parte. Los participantes que denominamos 'orador' y 'auditorio 'responden a las condiciones de transmisión y se activan mediante los deícticos personales. El participante que denominamos ‘destinatario’ (la ciudadanía) responde a que los discursos políticos proponen opciones en nombre del bien común, en beneficio de los destinatarios. El responsable de estas opciones es otro de los participantes destacados, el 'grupo del orador'. Por último, los 'adversarios' responden a que la acción social asociada a los discursos políticos se desarrolla en un contexto de elección donde hay otras opciones posibles no deseadas.

La distinción entre auditorio y destinatario equivale la de alocutor y destinatario indirecto -propuesta por Portolés (2004) basado en Goffman- o auditorio y receptor (cf. Vilches et al., 2007). Por su parte, la distinción entre el grupo propio y los adversarios se basa en la tradicional dinámica de la ideología resumida en el 'nosotros' frente a 'los otros’ (cf. Duszak, 2002) o la autorepresentación positiva y presentación negativa de los otros (cf. Van Dijk, 1999). 
En definitiva, la estructura del discurso electoral que proponemos se basa en una exposición oral en la que hay solapada una argumentación. Los discursos iniciales y finales de dicha estructura se caracterizan por la alta densidad de deícticos. El discurso inicial mantiene una relación de elaboración con el resto del texto. El discurso final contiene el referente característico de este tipo de discurso, la presentación de un escenario electoral futuro y la petición de voto. Este discurso final mantiene relaciones causales con los discursos intermedios, entendiéndose de este modo como razones para el voto. Estos discursos intermedios se caracterizan porque cada uno está articulado por cadenas correferenciales que remiten a un tipo diferente de los participantes propuestos; es decir, el texto progresa por el cambio en los valores de esta categoría referencial.

\section{Análisis de un discurso electoral}

Como ilustración del modelo de estructura textual propuesto, analizamos un discurso de Esperanza Aguirre, candidata del Partido Popular a las elecciones de la región de Madrid. El discurso forma parte de la campaña de las elecciones autonómicas de octubre de 2003. Tras las elecciones anteriores, en mayo de ese mismo año, la alianza entre Izquierda Unida y el Partido Socialista no consiguió formar gobierno debido a un episodio de transfuguismo de dos diputados socialistas. La lista encabezada por Esperanza Aguirre fue la más votada en las elecciones de mayo y obtuvo mayoría absoluta en las elecciones de octubre. El discurso del ejemplo fue pronunciado el 11 de septiembre de 2003 en un acto organizado por las Nuevas Generaciones del Partido Popular. Consta de 1055 palabras y 39 oraciones.

\subsection{Método}

El análisis se realiza en dos fases. En primer lugar, el texto se segmenta en discursos atendiendo a la referencia a los participantes mediante el estudio de las cadenas correferenciales. En segundo lugar, se propone el análisis de las relaciones que establecen los discursos resultantes de la segmentación.

Para la anotación de los elementos textuales que forman parte de las cadenas, son necesarias dos consideraciones previas: hay que decidir qué participantes forman parte del 
análisis y hay que evitar la doble anotación o anotación redundante. En cuanto a los participantes analizados, se consideran los cinco tipos expuestos en el apartado anterior. Aunque no formen cadenas correferenciales, se decide anotar siempre los elementos textuales con referencia al auditorio y orador. El orador está representado por los deícticos personales de primera persona. El auditorio también está representado por deícticos y además, por los vocativos. La única advertencia para la anotación del auditorio es su diferenciación de los 'destinatarios' cuando los deícticos personales remitan a estos últimos. El ejemplo 2, un extracto del discurso analizado, ilustra cómo unos deícticos se refieren al auditorio y otros a los destinatarios. En la oración 2, 'vosotros', 'trasladaros’ y 'escucharos' se refieren al auditorio, las personas de la situación de enunciación; como corrobora el resto de referencias a dicha situación: 'esta es una magnífica oportunidad’ y 'hoy'. Sin embargo, en la oración 3, este auditorio se identifica con todo un grupo social: 'los jóvenes'. En esta oración, el posesivo y los morfemas verbales de segunda persona, 'vuestro' y 'vais' no se refieren exclusivamente a las personas de la enunciación; sino a los destinatarios, que no siempre están representados mediante deícticos. Los destinatarios, el grupo de la oradora y los adversarios pueden tomar diferentes valores dentro de un mismo texto. Para simplificar la anotación, no todos los posibles valores son considerados. Solo se anotan aquellos que construyen en algún lugar del texto al menos una cadena correferencial que afecte a varias oraciones.

(2) [2] Esta es una magnífica oportunidad de hablar con vosotros, de trasladaros mi punto de vista, nuestro programa y, lo más importante, de escucharos, que es hoy lo que más me interesa.

[3] Los jóvenes vais a ser los protagonistas de esta campaña electoral y con vuestro voto vais a decidir si conseguimos una mayoría suficiente.

Otra de las precauciones sobre la anotación es la de evitar la doble anotación o anotación redundante. El caso más frecuente de doble anotación ocurriría cuando los morfemas de persona estén acompañados de un sujeto explícito. En estos casos, el sintagma nominal o la proforma del sujeto y el morfema verbal de persona activan conjuntamente el mismo participante, por lo que se propone que solo sea anotado el sujeto. También, en las oraciones atributivas, cuando los dos argumentos remiten al mismo participante se anota solo uno de ellos.

En cuanto a la segunda fase del análisis, el estudio de las relaciones entre discursos, hay que considerar dos tipos de relaciones. En primer lugar, las relaciones exigidas por el tipo de texto, las reflejadas en la figura 1, pueden ser implícitas. Las relaciones 
implícitas se comprueban introduciendo un marcador de discurso de modo que no se modifique la representación semántica del discurso. En segundo lugar, además de las relaciones entre discursos exigidas por el tipo de texto, en cada texto concreto pueden construirse relaciones adicionales entre los discursos.

\subsection{Segmentación textual: identificación de los discursos}

A continuación incluimos el texto íntegro del discurso con la anotación de los participantes. El código de anotación P1 corresponde a la oradora; P2, al auditorio; P3, a su grupo político; P5 y P8, a los adversarios, 'Partido Socialista’ e ‘Izquierda Unida'. Hay tres tipos de destinatarios: P4 remite a 'los jóvenes', P6 a Madrid, los madrileños y los ciudadanos; P7 alude a expresiones generalizadoras referidas a personas, como cuantificadores existenciales o el uso generalizador de la primera persona del plural. La separación en párrafos es nuestra y señala los límites entre discursos, justificados por el cambio en la referencia de los participantes.

[1] [P1] Queridos amigos, para [P2] mí es un honor estar con [P1] vosotros en este acto de Nuevas Generaciones al que [P1] habéis tenido la amabilidad de [P2] invitarme. [2] Esta es una magnífica oportunidad de hablar con [P1] vosotros, de [P1] trasladaros [P2] mi punto de vista, [P3] nuestro programa y, lo más importante, de [P1] escucharos, que es hoy lo que más [P2] me interesa.

[3] [P4] Los jóvenes vais a ser los protagonistas de esta campaña electoral y con [P4] vuestro voto [P4] vais a decidir si [P3] conseguimos una mayoría suficiente. [4] Una mayoría sólida, capaz de llevar adelante un proyecto que signifique un progreso para los más de un millón de [P4] jóvenes que vivís en nuestra comunidad. [5] [P4] Vosotros sois la generación más formada y capaz de las que ha tenido España. [6] Y eso molesta a [P5] muchos porque [P5] saben que [P4] sois ciudadanos críticos, impermeables a la demagogia y capaces de discernir entre los modelos que [P4] os ofrecen [P3] [P5] unos y otros.

[7] [P6] La Comunidad de Madrid ha vivido una situación que nadie deseaba, que ha significado una parálisis institucional, pero que ha dejado muy claro cómo son [P5] unos, qué talante tienen y qué políticas [P5] pueden traer [P6] a la Comunidad, y cómo [P3] nos comportamos los miembros del Partido Popular. [8] Hoy ya [P7] sabemos que el [P5] Partido Socialista ha caído en una vorágine de radicalismo y de divisiones internas y es necesario decirlo públicamente. [9] Porque [P5] ellos pretenden pasar de puntillas. [10] Pero es importante poner de manifiesto que, si no [P3] ganamos las elecciones, la Consejería de Educación, por ejemplo, un departamento que [P4] os influye directamente a los jóvenes, puede pasar a manos de un partido como es [P8] Izquierda Unida, que [P8] ha caído en la incoherencia y en el radicalismo más absoluto. [11] Hace poco [P7] pudimos oír debates disparatados de [P8] esta formación que [P8] llegaba a pedir la necesidad de que Andalucía sea definida como "nacionalidad en construcción" o "nacionalidad histórica" o que [P8] van de la mano de Lehendakari con el plan Ibarretxe debajo del brazo, quebrando el modelo constitucional español. [12] Esto es lo que [P7] nos ofrece [P8] la formación de Fausto Fernández y, [P5] estos, son los compañeros de viaje de [P5] Rafael Simancas. [13] Por cierto, dice [P5] el candidato socialista que [P3] nosotros no tenemos con quien pactar y, que [P5] ellos en cambio si pueden pactar. [14] Habría que [P5] recordarle que [P3] estamos dispuestos a pactar porque [P3] somos una fuerza política de centro y moderada, con partidos que no pongan en duda los pilares fundamentales de nuestro ordenamiento constitucional pero no en caer en los brazos de nacionalistas, regionalistas o [P8] comunistas donde más [P5] les conviene y, sobre todo, donde más [P5] les garantiza el poder. [15] Y también es [P3] nuestra obligación [P1] poneros de manifiesto que la [P5] FSM no es un bloque unido, sino grupúsculos inconexos que sólo [P5] están unidos por el deseo de gobernar y por el afán de alcanzar el presupuesto. [16] [P7] Hemos sido testigos estos meses de que [P5] viven instalados en el odio tribal y que [P5] resuelven las diferencia internas en [P5] este partido expulsando a los afiliados de 70 años por ser el padre de uno, apartando a personas como [P5] Cristina Alberdi por expresar libremente su opinión.

[17] [P3] Nosotros hemos demostrado, una vez más en esta crisis, que [P3] somos un partido moderado, de centro reformista, unido en torno a unos valores y unos principios que han construido [P3] nuestra ideología, pero sobre todo, que [P3] somos gente de fiar. [18] Personas con sentido común, que [P3] estamos en política para mejorar las cosas, personas honradas y trabajadores que [P3] hacen de la política su vocación. [19] [P3] Somos un partido con un proyecto claro y definido para los [P4] jóvenes. [20] Hace 3 meses [P4] os [P3] presentamos un programa que tenía como eje fundamental 
crear una sociedad de oportunidades real para [P4] vosotros. [21] Por eso, [P3] entendimos que [P3] nuestra obligación era plantear soluciones concretas para el problema de la emancipación, el empleo y la vivienda. [22] Para ello, [P3] pondremos a disposición de [P4] los menores de 35 años, 75.000 viviendas con un precio de 6 euros por metro cuadrado, entre 50 y 70 metros, para paliar el problema de la vivienda [P4] joven. [23] Además, [P3] estableceremos en el tramo autonómico del IRPF, para los [P4] jóvenes, una deducción por arrendamiento de vivienda habitual del $20 \%$ del alquiler con un máximo de 840 euros. [24] Y [P3] crearemos 225.000 puestos de trabajo, especialmente para mujeres y [P4] jóvenes, con la legitimidad que [P3] nos da haber reducido [P4] vuestro paro en un 21, 8\%. [25] [P3] Daremos un empuje especial a la formación profesional, con la creación y puesta en funcionamiento de centros integrados que aglutinen la formación profesional reglada, continua y ocupacional e incrementar el 50\% de los fondos destinados a dotar becas de 601 euros mensuales a [P4] jóvenes desempleados.

[26] [P1] Queridos amigos, cuando [P7] supimos los resultados del 25 de mayo [P7] nadie se podía esperar que habría nuevas elecciones. [27] [P7] Nadie podía esperar que el [P5] PSOE no hubiera sabido configurar sus listas. [28] [P7] Nadie podía esperar que [P8] IU exigiera hasta el 50\% del Gobierno regional, pero desde luego, lo que [P7] nadie podía esperar, es que [P5] los socialistas decidieran trasladar a las instituciones [P5] sus problemas internos y, lo que es más grave, intentar [P3] acusarnos de estar detrás de [P5] sus problemas. [29] Se [P5] han llenado la boca de hablar de golpe a la democracia. [30] Pero la realidad es que [P7] estamos en esta situación creada por [P5] ellos y, que con [P5] su actitud, [P5] su incapacidad de asumir responsabilidades, [P5] su intento de trasladar su problema a la sociedad y a [P3] nuestro partido con un talante inquisitorial, [P5] han provocado un grave daño a las instituciones madrileñas.

[31] Ahora [P7] tenemos por delante casi cuatro años en los que [P3] el Partido Popular va a demostrar a [P6] los ciudadanos que [P3] es capaz de resolver [P6] sus problemas y no de creárselos, de encontrar zonas de consenso entre todas las formaciones políticas, con capacidad de diálogo y de encuentro. [32] De anteponer los intereses generales a los particulares. [33] [P3] Seremos merecedores de la enorme confianza que [P3] nos [P6] den los madrileños y la [P3] utilizaremos para hacer realidad las enormes potencialidades que [P6] tiene nuestra comunidad. [34] Hoy hay [P3] un partido político que representa la rebeldía en nuestra sociedad. [35] [P3] Que representa el inconformismo ante los problemas que la afectan. [36] [P3] Un partido que tiene una idea clara de donde está hoy [P6] Madrid y donde podemos, entre [P6] todos, [P6] colocarla en cuatro años.

[37] Y [P4] vosotros, los jóvenes, estáis en el centro de esa transformación. [38] Para hacer frente a este proyecto [P4] os [P2] pido [P4] vuestra confianza, la confianza de [P4] los jóvenes, porque con [P4] vuestra ilusión y empuje el próximo 26 de Octubre, [P6] Madrid tendrá [P3] el Gobierno que [P6] se merece. [39] Muchas gracias.

La tabla 1 muestra los resultados de la anotación (realizada mediante la aplicación UAM Corpus Tool de O’Donnell, 2008). La tabla presenta las repeticiones de cada participante y la proporción respecto a las repeticiones de todos los participantes en cada uno de los discursos propuestos. Las celdas sombreadas en oscuro señalan los participantes principales de cada unidad discursiva; las sombreadas en claro indican cambios significativos en las densidades respecto a las unidades de discurso adyacentes.

\begin{tabular}{|c|c|c|c|c|c|c|c|c|c|c|c|c|c|c|}
\hline Oraciones $\rightarrow$ & \multicolumn{2}{|l|}{$[1-2]$} & \multicolumn{2}{|l|}{$[3-6]$} & \multicolumn{2}{|c|}{$[7-16]$} & \multicolumn{2}{|c|}{$[17-25]$} & \multicolumn{2}{|c|}{ [26-30] } & \multicolumn{2}{|c|}{$[31-36]$} & \multicolumn{2}{|c|}{ [37-39] } \\
\hline Palabras $\rightarrow$ & \multicolumn{2}{|l|}{55} & \multicolumn{2}{|l|}{91} & \multicolumn{2}{|l|}{352} & \multicolumn{2}{|l|}{253} & \multicolumn{2}{|l|}{136} & \multicolumn{2}{|l|}{133} & \multicolumn{2}{|l|}{35} \\
\hline Variables $\downarrow$ & $\%$ & $\mathrm{~N}$ & $\%$ & $\mathrm{~N}$ & $\%$ & $\mathrm{~N}$ & $\%$ & $\mathrm{~N}$ & $\%$ & $\mathrm{~N}$ & $\%$ & $\mathrm{~N}$ & $\%$ & $\mathrm{~N}$ \\
\hline PARTICIPANTES & \multicolumn{2}{|c|}{$N=11$} & \multicolumn{2}{|c|}{$\mathrm{N}=11$} & \multicolumn{2}{|l|}{$\mathrm{N}=38$} & \multicolumn{2}{|l|}{$\mathrm{N}=24$} & \multicolumn{2}{|c|}{$\mathrm{N}=23$} & \multicolumn{2}{|c|}{$\mathrm{N}=17$} & \multicolumn{2}{|l|}{$N=8$} \\
\hline Oradora [P2] & 36.4 & 4 & 0.0 & 0 & 0.0 & 0 & 0.0 & 0 & 0.0 & 0 & 0.0 & 0 & 12.5 & 1 \\
\hline Auditorio [P1] & 54.5 & 6 & 0.0 & 0 & 2.6 & 1 & 0.0 & 0 & 4.4 & 1 & 0.0 & 0 & 37.5 & 3 \\
\hline Destinatarios [P4] [P6] [P7] & 0.0 & 0 & 54.6 & 6 & 23.7 & 9 & 37.5 & 9 & 34.8 & 8 & 52.9 & 9 & 37.5 & 3 \\
\hline Partido propio [P3] & 9.1 & 1 & 18.2 & 2 & 15.8 & 6 & 62.5 & 15 & 8.7 & 2 & 47.1 & 8 & 12.5 & 1 \\
\hline Adversarios [P5] [P8] & 0.0 & 0 & 27.3 & 3 & 57.9 & 22 & 0.0 & 0 & 52.2 & 12 & 0.0 & 0 & 0.0 & 0 \\
\hline DESTINATARIOS & \multicolumn{2}{|l|}{$\mathrm{N}=0$} & \multicolumn{2}{|l|}{$\mathrm{N}=6$} & \multicolumn{2}{|l|}{$\mathrm{N}=9$} & \multicolumn{2}{|l|}{$N=9$} & \multicolumn{2}{|l|}{$\mathrm{N}=8$} & \multicolumn{2}{|l|}{$\mathrm{N}=9$} & \multicolumn{2}{|l|}{$N=3$} \\
\hline Jóvenes [P4] & 0.0 & 0 & 100 & 6 & 11.1 & 1 & 100.0 & 9 & 0.0 & 0 & 11.1 & 1 & 33.3 & 1 \\
\hline Madrid-y-madrileños [P6] & 0.0 & 0 & 0.0 & 0 & 33.3 & 3 & 0.0 & 0 & 37.5 & 2 & 66.6 & 4 & 66.7 & 2 \\
\hline Generalización [P7] & 0.0 & 0 & 0.0 & 0 & 55.6 & 5 & 0.0 & 0 & 62.5 & 6 & 22.2 & 2 & 0.0 & 0 \\
\hline ADVERSARIOS & \multicolumn{2}{|l|}{$\mathrm{N}=0$} & \multicolumn{2}{|l|}{$\mathrm{N}=3$} & \multicolumn{2}{|c|}{$\mathrm{N}=22$} & \multicolumn{2}{|l|}{$\mathrm{N}=0$} & \multicolumn{2}{|c|}{$\mathrm{N}=12$} & \multicolumn{2}{|l|}{$\mathrm{N}=0$} & $\mathrm{~N}=0$ & \\
\hline Adversarios gral. y socialistas [P5] & 0.0 & 0 & 100 & 3 & 72.8 & 16 & 0.0 & 0 & 91.7 & 11 & 0.0 & 0 & 0.0 & 0 \\
\hline Izquierda Unida [P7] & 0.0 & 0 & 0.0 & 0 & 27.3 & 6 & 0.0 & 0 & 8.3 & 1 & 0.0 & 0 & 0.0 & 0 \\
\hline
\end{tabular}

Tabla 1. Repeticiones de los participantes en cada discurso 
La figura 2 muestra el flujo y la densidad de los participantes a lo largo de sus oraciones. El eje de abscisas representa las oraciones y el de coordenadas las repeticiones de cada participante. En el gráfico se comprueba a simple vista como cada discurso se caracteriza por la referencia a unos participantes determinados y por los cambios respecto a los discursos adyacentes. Las líneas verticales señalan los límites entre discursos; en los próximos apartados se detalla y justifica la segmentación textual basada en la referencia a los participantes. Asimismo, se analizan otras indicaciones lingüísticas que confirman la segmentación propuesta; entre las que destacan los cambios y continuidad de la referencia temporal y algunas indicaciones puntuales sobre la estructuración temático-discursiva .

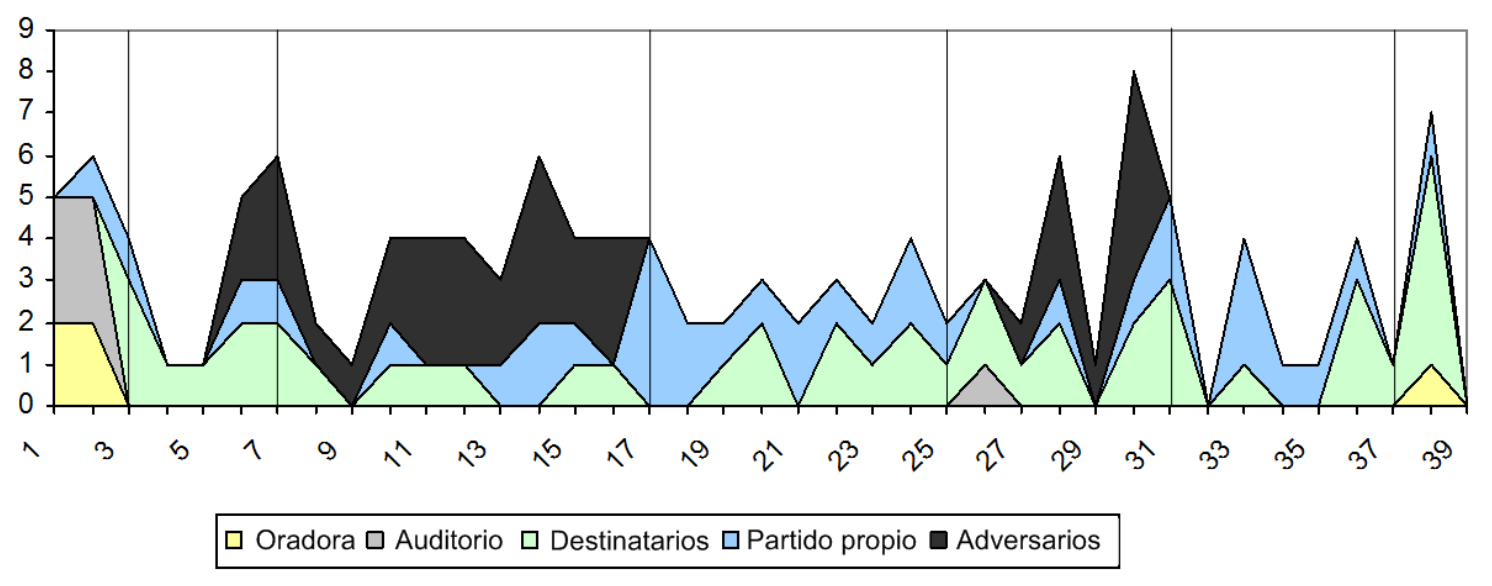

Figura 2. Distribución de los participantes en el texto y límites entre discursos

Primer discurso [1-2]. El conjunto de oraciones 1-2 se caracteriza por la deixis personal a la oradora (P2) y a su auditorio (P1), que cubren el 91\% de la referencia a los participantes de este discurso. Como la oradora solo aparece en este primer discurso y en el último, su importancia relativa es mayor. En cuanto a la referencia temporal, destaca el presente. Además de los tiempos verbales, otros deícticos temporales y espaciales remiten a la situación de enunciación; nótese 'este acto', 'esta es una magnífica oportunidad' o 'es hoy'. La segunda oración contiene el procedimiento catafórico propio de las primeras unidades de las presentaciones orales. Esta oración categoriza de forma vaga la acción social en la que se incluye el discurso; la categorización que afecta en mayor medida al contenido del texto es 'trasladaros nuestro punto de vista, nuestro programa’. Gracias a la mención del programa electoral, la 
catáfora confirma las expectativas de género del discurso electoral. En definitiva, la referencia destacada a los participantes P1 y P2 y la presencia de la catáfora textual definen la primera unidad de discurso.

Segundo discurso [3-6]. La segunda agrupación de oraciones se caracteriza por la referencia destacada a los destinatarios, que representan más de la mitad de los participantes de este discurso. El auditorio al que se dirige en el discurso precedente, las personas presentes en el lugar del discurso, es ampliado al grupo más amplio al que pertenecen: los jóvenes. Otro cambio referencial que justifica en gran medida la segmentación es la desaparición completa de la propia oradora. También se introduce un nuevo referente, los adversarios políticos, concentrados en la última oración, 6, que actúa como bisagra con el siguiente discurso, articulado por este participante. Las características temporales diferenciadas respecto a la unidad de discurso anterior confirman la segmentación propuesta. En este discurso se introduce el futuro; nótese 'vais a ser' y 'vais a decidir'. Continúa el uso del presente, que adquiere un matiz generalizador, frente al presente puntual de las oraciones precedentes.

Tercer discurso [7-16]. El tercer discurso está articulado por los adversarios políticos, P5 y P7. La referencia al Partido Popular, P4, es secundaria, pero aparece en la práctica totalidad de las oraciones del conjunto. La desaparición casi completa de los jóvenes confirma la frontera con el discurso anterior, articulado en torno a este referente. Las características temporales y aspectuales confirman la segmentación. Frente a la unidad discursiva anterior centrada en el futuro, en esta unidad destaca el pasado: 'ha vivido', 'ha significado', 'ha dejado’, 'ha caído’, ‘pudimos oír', ‘llegaba a pedir’ o 'hemos sido'. La referencia al pasado se ubica en un escenario político excepcional, 'una situación que nadie deseaba’: la repetición de las elecciones. La temporalidad centrada en el pasado convive con el uso del presente con funciones generalizadoras: 'son', 'comportamos', 'tenemos’, ‘estamos', ‘somos’, ‘conviene’, 'garantiza', 'viven’, 'resuelven’, etcétera. El presente, en combinación con el uso generalizador de la primera persona del plural se utiliza para introducir las repercusiones actuales del escenario pasado: 'hoy ya sabemos’ o ‘esto es lo que nos ofrece'. 
Cuarto discurso [17-25]. El cuarto discurso se caracteriza por la referencia al partido propio (P3) que destaca frente a su baja frecuencia en el discurso anterior. La segmentación se confirma por la desaparición del participante que caracterizaba aquel discurso, los adversarios. Una razón más que apoya la segmentación es la reaparición de los jóvenes (P4), que representan el $37 \%$ de los participantes. Las cadenas correferenciales en torno a los jóvenes y a su partido articulan esta unidad de discurso. En cuanto a la temporalidad, destaca la reintroducción del futuro, ausente en la unidad anterior.

Quinto discurso [26-30]. El quinto conjunto de oraciones está articulado por la referencia a los adversarios políticos, P5 y P7, que representan el 50\% de los participantes de esta unidad; frente a su ausencia en la unidad anterior. La referencia al partido propio, que caracterizaba la unidad discursiva precedente, disminuye considerablemente. Continúa la referencia a los destinatarios, que pasan de identificarse con los jóvenes a un nuevo valor más amplio representado mediante la primera persona del plural con valor genérico ('cuando supimos’), cuantificadores existenciales ('nadie’) o sustantivos colectivos ('sociedad'). En cuanto a la referencia temporal, destaca el pasado (v. g. 'supimos' o 'podía') que remite al escenario y tema excepcional que caracterizaba a la tercera unidad, la repetición de las elecciones. El vocativo en la primera oración (26) de esta unidad confirma la segmentación propuesta por las cadenas correferenciales. En los discursos políticos, los vocativos añaden a la función de 'control de contacto' (Briz, 1998) o de 'enfocador de alteridad' (Martín Zorraquino y Portolés, 1999), la de 'estructuración temático-discursiva’ (cf. Bañón 1993). Esta función en la estructuración del texto está limitada a ciertos tipos de textos; según aprecia Longracre (1983), a textos 'expositivos y exhortativos', como las epístolas bíblicas (cf. Longracre, 1992). También en los discursos políticos, Cortés (2011 y 2012b) ilustra el papel de los vocativos como marcador secuencial. En el texto del análisis, antes del vocativo 'queridos amigos', la referencia se concentra en los participantes P3 y P1, después en P5. También, antes del vocativo destaca la referencia al futuro; y después, se introduce el pasado. Lo que confirma la segmentación basada en la referencia temporal y a los participantes. 
Sexto discurso [31-36]. En el sexto grupo de oraciones desaparece la referencia a los adversarios políticos y aumenta la densidad de la referencia al partido propio y a los destinatarios, que representan respectivamente, el 39\% y 61\% de los participantes. La referencia a los destinatarios remite principalmente a los ciudadanos y madrileños, con una referencia aislada a los jóvenes. En cuanto a la temporalidad, la reintroducción del futuro marca otra diferencia respecto a la unidad anterior; nótese 'va a demostrar' y 'seremos'. La referencial temporal futura se sitúa en la legislatura que sigue a las elecciones, 'tenemos por delante casi cuatro años’.

Séptimo discurso: [37-39]. El último grupo, 37-39, recupera la referencia directa al auditorio, que combina con la ampliación a todos los jóvenes. Se reintroduce la propia oradora con la primera persona del singular. En cuanto a la temporalidad, se sitúa en el presente y en el futuro. En esta unidad de discurso se incluye el tipo de referente clave del discurso electoral, la presentación del escenario futuro de elección, con la petición del voto en la oración 38. A lo largo del texto hay otras referencias explícitas al escenario electoral, en 3 y 27, pero no ocupan la posición central del modo en que lo hace en este discurso. Por otra parte, las anáforas ‘esa transformación’ y ‘este proyecto', en 37 y 38, remiten a la representación construida en el discurso anterior, confirmando la segmentación.

Las siete unidades de discurso detectadas cumplen con los requisitos semánticos locales de los discursos electorales. En el primer y último discurso destacan los deícticos. En último discurso se expone un escenario electoral futuro y se pide el voto. El resto de discursos están articulados por cadenas correferenciales en torno a diferentes participantes; progresando el texto por el cambio en esta categoría referencial.

\subsection{Relaciones entre discursos}

Los siete discursos detectados cumplen los requisitos semánticos locales de la estructura de los discursos electorales. Para completar la descripción de la estructura textual, las siete unidades discursivas deben ajustarse al molde de los discursos políticos, que consiste en una presentación oral en la que hay solapada una estructura argumentativa. La figura 1 presenta esta estructura textual, detallada en términos de relaciones de 
coherencia entre las unidades de discurso. Las relaciones propuestas se comprueban si la introducción de los marcadores de discurso que las hacen explícitas no altera la representación semántica del texto. Adicionalmente, los discursos pueden mantener relaciones no previstas en la estructura textual del tipo de texto. En el análisis también atendemos a estas últimas relaciones.

Unidades de la presentación oral y conclusión de la argumentación. La deixis a la situación de enunciación define la primera y última unidad de discurso, 1-2 y 37-39. En la primera unidad se introduce el tema de discurso ('esta es una magnífica oportunidad de hablar con vosotros, de trasladaros mi punto de vista, nuestro programa') que propone la relación de elaboración con el resto del texto. Por su parte, el último discurso introduce el escenario electoral y la petición de voto. Este último discurso se establece en la posición más alta de la jerarquía textual como conclusión de la argumentación, de modo que propone relaciones de causa con los discursos intermedios. Así, los discursos intermedios, 3-6, 7-16, 17-25, 26-30 y 31-36, se entienden como razones que apoyan el voto a la opción del orador.

Primera razón: elogios a los destinatarios. El discurso 3-7 se caracteriza por la referencia a los destinatarios, los jóvenes. Este discurso funciona como un tipo de argumento que consiste en la presentación del aprecio del orador a su público -al que desprecian los adversarios-. En este sentido, la tercera oración, 'vais a ser los protagonistas de la campaña electoral', presenta la importancia de los destinatarios. Además, la referencia al escenario electoral en el comienzo del discurso confirma el tipo de texto. Este discurso se adapta al modelo del tipo de texto mediante una relación causal implícita, que podemos parafrasear utilizando el marcador causal: 'votad al Partido Popular porque nosotros os apreciamos, apreciamos a los jóvenes; nuestros adversarios no’. Este axioma muestra como un contenido determinado, la valoración positiva, eleva su importancia en la representación semántica para conectar con éxito los dos discursos. 
Segunda razón: deslegitimación del adversario. La unidad 7-16 se caracteriza por la referencia a los adversarios políticos, por el presente generalizador que sirve para la valoración y por los tiempos verbales en pasado que remiten a la situación excepcional de la repetición de las elecciones. Ya que este discurso es premisa de una argumentación, las tres características revelan la estrategia política de la deslegitimación, -otro de los argumentos recurrentes en este tipo de texto-. Para el ajuste al modelo propio del tipo de texto se establece una relación causal implícita que puede parafrasearse haciendo explícita la relación causal: 'Nuestros adversarios son radicales, incoherentes, han provocado una situación indeseable y debates disparatados, por eso votadnos a nosotros; no votéis al Partido Socialista'.

Tercera razón: comparación entre partidos. La anáfora de su primera oración de 1725, 'esta crisis', mantiene en la representación del discurso el escenario de la unidad anterior, ‘una situación que nadie deseaba', la repetición de las elecciones. Sin embargo, la posición temática de esta primera oración está ocupada por 'nosotros’, lo que marca una relación de comparación con el discurso anterior, caracterizado por 'ellos', los adversarios políticos. La relación se confirma en la primera oración de 7-16, donde se introducen indicaciones generales sobre la comparación: 'una situación que nadie deseaba (...) que ha dejado muy claro cómo son unos, qué talante tienen y qué políticas pueden traer a la comunidad, y cómo nos comportamos los miembros del Partido Popular'. El valor de las incógnitas planteadas por los interrogativos de dicha oración se resuelve en ese discurso y en el siguiente, desarrollando la comparación anunciada. Así, la relación de comparación de 7-16 y 17-25 construye una unidad superior que también funciona como premisa de la argumentación; y que podemos parafrasear a grandes rasgos como: 'votadnos a nosotros porque somos mejores que ellos'. La figura 3 ilustra estas dos relaciones y el resto de la estructura textual descrita hasta el momento. 


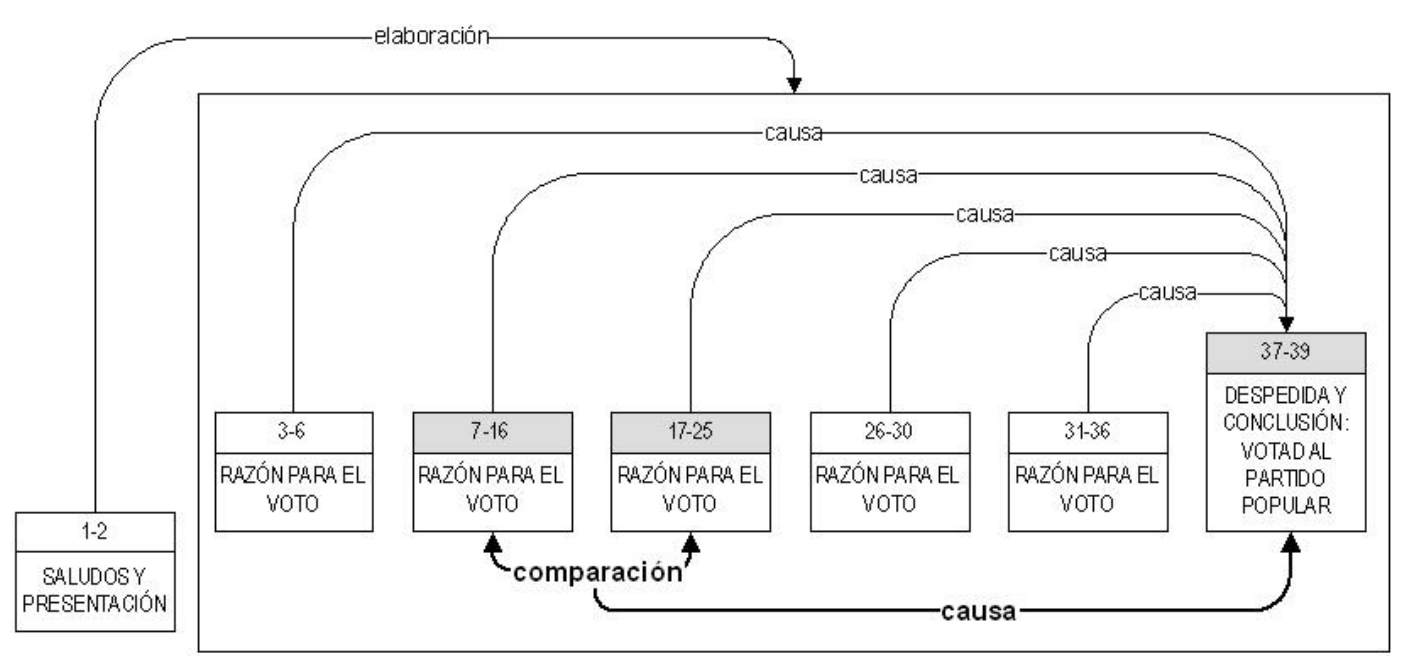

Figura 3. Relaciones entre discursos de causa y comparación

Cuarta razón: legitimación del partido propio y promesas electorales. El discurso 1725 también funciona por sí solo como razón. Aunque al comienzo de la unidad se active el escenario pasado de la repetición de las elecciones, en 17-25 destacan los tiempos verbales del presente y futuro. Lo hecho durante la crisis de la repetición de las elecciones sirve como ejemplo de las esencias del partido y de lo que se hará si se consigue la victoria. Las características de este discurso -la referencia destacada al futuro, partido propio y destinatarios- construyen otro argumento recurrente cuando establecen la relación causal exigida. Dicho argumento consiste en las promesas electorales; a grandes rasgos, 'vótanos porque haremos esto'. Junto con las promesas, en este discurso presenta positivamente al partido de la oradora. En definitiva, el discurso se ajusta al esquema del tipo de texto mediante la construcción de la relación causal implícita que puede parafrasearse como: 'Votadnos porque somos un partido moderado, un proyecto claro para los jóvenes, con personas honradas, con vocación, gente de fiar, con principios y valores y porque crearemos puestos de trabajo, estableceremos deducciones en el tramo autonómico del IRPF y paliaremos el problema de la vivienda joven’.

Quinta razón: elaboración de la deslegitimación. La unidad 26-30 recupera la referencia central a los adversarios políticos. También destaca la referencia al pasado, que recupera el escenario de la repetición de las elecciones. Los tres valores referenciales -adversarios, pasado y el escenario de la repetición de las eleccionescoinciden con los de la unidad, más extensa, 7-16; lo que apunta a una relación de elaboración entre las dos unidades de discurso. Tanto esta relación como la anterior de 
comparación, no están exigidas por el tipo de texto, no son convencionales sino construidas por los procedimientos descritos. Sí es una exigencia del tipo de texto la relación causal implícita y convencional con la conclusión, que continúa el argumento introducido por 7-16 y que puede parafrasearse como: 'El Partido Socialista ha provocado estas nuevas elecciones por no saber configurar sus listas, es un partido irresponsable que traslada sus problemas a la ciudadanía; por eso no los votéis, votadnos a nosotros.' La figura 4 ilustra la relación de causa y la de elaboración y el resto de la estructura textual descrita hasta el momento.

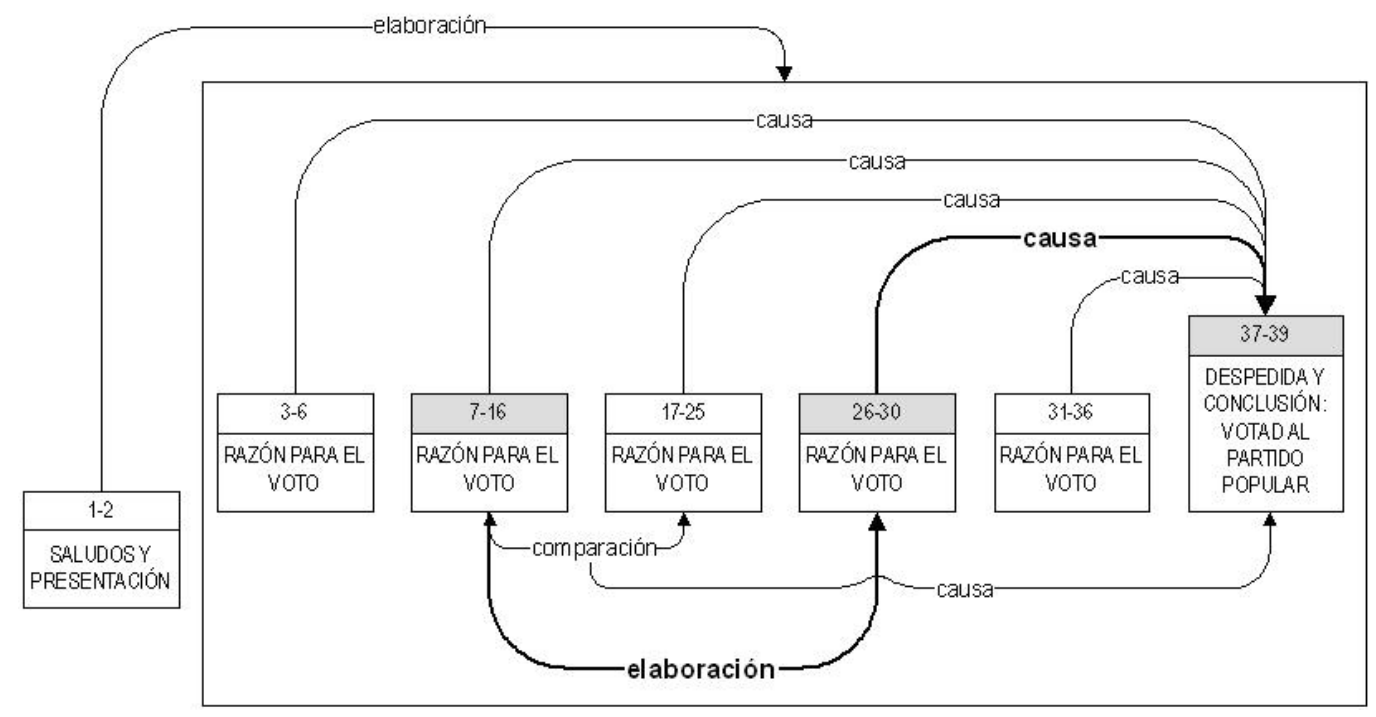

Figura 4. Relaciones entre discursos de causa y elaboración

Sexta razón: elaboración de la legitimación y promesas electorales. El discurso 3136 recupera el tema de la presentación positiva del Partido Popular y de las promesas electorales -mediante el uso del futuro-, lo que apunta a una relación de elaboración con 17-26. En el siguiente discurso, dos anáforas conceptuales categorizan la unidad precedente sobre las promesas electorales como 'este proyecto'; y a sus efectos como ‘esa transformación’. El discurso que nos ocupa, 31-36, se ajusta al esquema prototípico del tipo de texto mediante la construcción de la relación causal con la conclusión que podemos parafrasear como: 'El Partido Popular va a resolver los problemas de los ciudadanos, será merecedor de su confianza, representa la rebeldía en la sociedad y tiene una idea clara de donde está Madrid y dónde puede colocarse, por eso votadnos’.

Séptima razón: comparación entre partidos. En la primera oración del discurso 3136, ‘ahora’ ocupa la posición temática. Gracias a esta posición se propone una relación 
de comparación con la unidad anterior situada en el escenario pasado de la repetición de las elecciones. Además, la contra-argumentación de la negación confirma la comparación entre discursos: 'ahora tenemos por delante casi cuatro años en los que el Partido Popular va a demostrar a los ciudadanos que es capaz de resolver sus problemas y no de creárselos’. En definitiva, durante la crisis de la repetición de las elecciones, los adversarios políticos crearon problemas a los ciudadanos y ahora el Partido Popular va a resolverlos. Esta comparación se encaja en el modelo del tipo de texto mediante la relación causal que podemos parafrasear, otra vez a grandes rasgos como: 'El Partido Popular es mejor opción que el Partido Socialista, por eso votad al Partido Popular'. Tras este discurso se introduce el de petición de voto, analizado al principio de este apartado. La figura 5 ilustra las últimas relaciones comentadas y presenta el resultado final de la estructura textual descrita. Las relaciones causales son implícitas y exigidas por el tipo de texto. El resto de relaciones son adicionales, por lo que están construidas explícitamente; frecuentemente, en las periferias de las unidades de discurso.

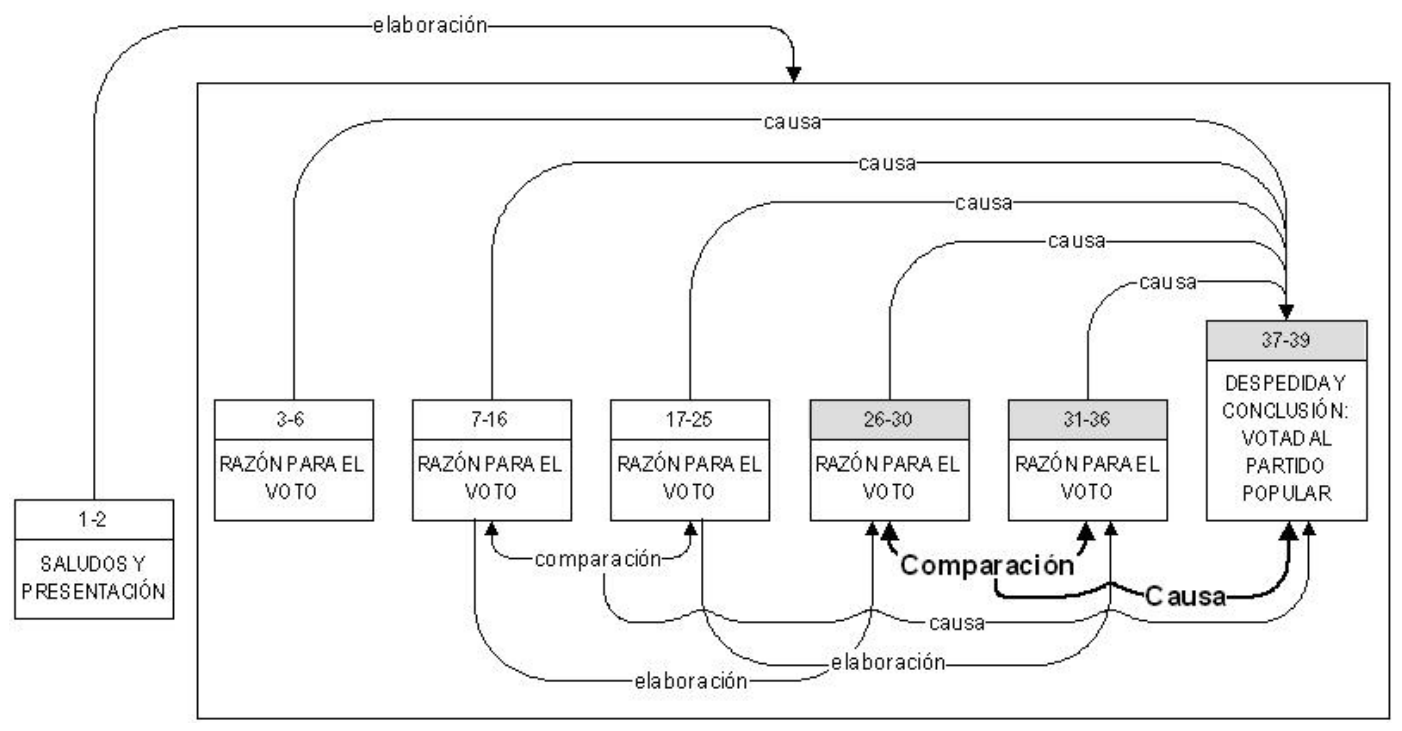

Figura 5. Estructura textual

\section{Conclusiones}

Frente a los géneros, que se definen a partir de las variables extralingüísticas de la acción social donde se enmarcan, los tipos de texto se definen por sus características lingüísticas (cf. Biber, 1988). La principal de ellas es la estructura textual. La estructura 
textual asociada a los tipos de texto es habitualmente descrita como una secuencia de etapas o movimientos (cf. Eggins y Martin, 1997; Swales, 1990). En este artículo comprobamos que la estructura textual asociada a los tipos de textos es más compleja que una estructura secuencial: es una estructura jerárquica en la que los componentes mantienen relaciones semánticas entre sí; relaciones que no están limitadas a los componentes adyacentes. En definitiva, la estructura textual que define a los tipos de textos se describe atendiendo a cuatro aspectos: a) la caracterización de cada componente de la estructura, b) el orden de aparición de cada componente, c) las relaciones semánticas que mantienen los componentes entre sí y d) la posición jerárquica de cada componente.

Los componentes de las estructuras se denominan movimientos (cf. Swales, 1990), etapas (cf. Eggins y Martin, 1997) o secciones (cf. Labov, 1972) y se caracterizan mediante requisitos de contenido. En este artículo seguimos el modelo de unidades propuesto por Garrido (2007) donde los textos estas constituidos por discursos. Vistos desde el tipo de texto, los discursos equivalen a los movimientos, etapas o secciones. Los discursos son unidades intermedias, entre el texto y la oración, a las que corresponden las propiedades de la cohesión y la coherencia (cf. Garrido, 1997). Por esta razón, en el análisis pudimos comprobar que los cambios en los elementos cohesivos del texto indicaban límites entre discursos. En el discurso analizado, los elementos cohesivos se organizaban en cadenas correferenciales. Los discursos resultantes de la segmentación se confirmaron con el estudio de otros elementos textuales como la continuidad y cambio en los tiempos verbales u otros elementos puntuales, como los vocativos que marcan la estructura temático-discursiva (cf. Bañón, 1993).

Los discursos se caracterizaron como los componentes de la estructura textual asociada al tipo de texto mediante la abstracción de las características de los referentes que articulaban los patrones de cohesión. En el caso del discurso electoral, cada componente de la estructura textual se articula por cadenas correferenciales que remiten a sus participantes prototípicos: orador, auditorio, destinatario, grupo del orador y adversarios. De este modo, siguiendo la recomendación de Paltridge (1994), en lugar de definir cada componente de la estructura textual por requisitos de contenido, se definen por cómo se expresa lingüísticamente; como hacen -aunque proponiendo diferentes análisis- Upton y Connor (2009) o Scott y Tribble (2006). 
Una vez caracterizados e identificados los componentes de la estructura textual, describimos su jerarquía y relaciones semánticas. Para ello, propusimos un análisis de las relaciones de coherencia (cf. Mann y Thompson, 1988) que mantienen los componentes entre sí. Hay relaciones de coherencia explícitas, señaladas mediante marcadores de discurso u otros procedimientos (cf. Duque, en prensa), y relaciones de discurso implícitas, aquellas para las que en principio no se encuentra ninguna señal lingüística que marque la relación. En el análisis, siguiendo a (Wolf y Gibson, 2006) comprobamos que las relaciones implícitas pueden detectarse porque la introducción del marcador de discurso asociado a la relación no altera la representación semántica del texto. Procediendo de este modo, se confirmaron las relaciones de coherencia causales que definen la estructura del discurso electoral.

En cuanto a la estructura textual del discurso electoral, propusimos e ilustramos un modelo donde la primera y última unidad de discurso están caracterizadas por la alta densidad de deícticos respecto al resto del texto; es decir, en estas unidades los participantes destacados son el auditorio y la oradora. Junto con la primera unidad, se introduce el tema o motivo del discurso, de modo que establece una relación de elaboración con el resto del texto. Junto con el último discurso se introduce la conclusión de una argumentación, que establece las mencionadas relaciones causales con los discursos intermedios. La conclusión de la argumentación se coloca en la posición más alta de la jerarquía textual y se caracteriza por la presentación de un escenario electoral futuro y por la petición del voto. Como se ha indicado, se comprobó que los discursos intermedios se caracterizan porque cada uno de ellos se articula en torno a la referencia a un tipo concreto de participante; es decir, el texto progresa por el cambio en esta categoría referencial. Los discursos intermedios son las causas o razones del resultado o conclusión, la petición del voto. Por esta razón, las representaciones semánticas de los discursos articulados por cadenas en torno al grupo de la oradora y al pasado se entienden como legitimaciones. Las representaciones articuladas por los adversarios políticos y centradas en el pasado se entienden como deslegitimaciones. Las representaciones sobre el grupo del orador y el futuro son las promesas electorales.

Además de las relaciones causales implícitas exigidas por la estructura del tipo de texto, en cada texto concreto pueden establecerse explícitamente relaciones adicionales entre unidades de discurso. En el discurso analizado, estas relaciones adicionales se 
construyeron en las oraciones periféricas de las unidades de discurso. Este hecho promueve la posibilidad de que en el discurso, como en la oración, la periferia izquierda esté especializada en la conexión. En la oración, esta es la posición para la conexión del discurso (cf. Garrido, 1997: 179 y ss.), donde aparecen preferentemente los marcadores. Es también en esta posición donde aparecen el resto de señales que construyen las relaciones de coherencia (cf. Duque, en prensa).

Bibliografía

Adam, Jean-Michel (1992): Les textes. Types et prototypes. Récit, description, argumentation, explication et dialogue. París: Nathan.

Alba-Juez, Laura (2009): Perspectives on Discourse Analysis: Theory and Practice. Newcastle upon Tyne: Cambridge Scholars Publishing.

Ariel, Mira (1994): Interpreting anaphoric expressions: a cognitive versus a pragmatic approach. En: Journal of Linguistics, 30 (1), pp. 3-42.

Asher, Nicholas y Alex Lascarides (2003): Logics of conversation. Cambridge: Cambridge University Press.

Bañón, Antonio Miguel (1993): El vocativo: propuestas para su análisis lingüístico. Barcelona: Octaedro.

Bassols, Margarida y Anna Torrent (1997): Modelos textuales: teoría y práctica. Barcelona: Octaedro. [Original en catalán de 1996]

Beaugrande, Robert-Alain de y Wolfgang Ulrich Dressler (1997): Introducción a la lingúística del texto. Barcelona: Ariel. [Original en inglés de 1981] [http://beaugrande.com/introduction_to_text_linguistics.htm] [30-10-2013]

Biber, Douglas (1988): Variation across speech and writing. Cambridge: Cambridge University Press.

Biber, Douglas; Connor, Ulla y Thomas Upton (2007): Discourse on the Move: Using corpus analysis to describe discourse structure. Amsterdam: John Benjamins. 
Briz, Antonio (1998): El español coloquial en la conversación. Esbozo de una pragmagramática. Barcelona: Ariel.

Calsamiglia Blancafort, Helena y Amparo Tusón Valls (2007): Las cosas del decir: Manual de análisis del discurso. Barcelona: Ariel. [2 $2^{\text {a }}$ edición actualizada; $1^{\text {a }}$ edición de 1999]

Calvi, Maria Vittoria (2010): Los géneros discursivos en la lengua del turismo: una propuesta de clasificación. En: Ibérica: Revista de la Asociación Europea de Lenguas para Fines Específicos, 19, pp. 9-32.

[http://www.aelfe.org/documents/01_19_Calvi.pdf] [30-10-2013]

Camacho Adarve, María Matilde (2007): Los géneros en el discurso oral español. En: Espéculo, 37. [http://www.ucm.es/info/especulo/numero37/generos.html] [30-102013]

Cortés Rodríguez, Luis (2011): El plano secuencial en los debates en torno al estado de la nación. I. El discurso del presidente. En: Círculo de lingüística aplicada a la comunicación, 46, pp. 3-50. [http://www.ucm.es/info/circulo/no46/cortes.pdf] [13-09-2012]

Cortés Rodríguez, Luis (2012a): Los límites del discurso: condicionantes y realizaciones. En: Círculo de lingüística aplicada a la comunicación, 51, pp. 3-49. [http://www.ucm.es/info/circulo/no51/cortes.pdf] [15-11-2012]

Cortés Rodríguez, Luis (2012b): La serie enumerativa en el cierre de los discursos. Estudios filológicos, 49, pp. 39-57.[http://www.scielo.cl/pdf/efilolo/n49/art03.pdf] [12-10-2012]

Cortés Rodríguez, Luis (2013): El inicio y el cierre: dos unidades ilocutivo-textuales en el entramado del análisis del discurso. XLII Simposio de la Sociedad Española de Lingüística. Madrid, enero de 2013.

Duque, Eladio (2009): Batallas internas en la comunicación política: estructura retórica y construcción de los participantes en un discurso de Esperanza Aguirre. En: Discurso y Sociedad, 3 (4), pp. 658-681.

[http://www.dissoc.org/ediciones/v03n04/DS3\%284\%29Duque.pdf] [30-10-2013] 
Duque, Eladio (en prensa): Signaling causal coherence relations. En: Discourse Studies.

Duszak, Anna (ed.) (2002): Us and Others: social identities across languages, discourses and cultures. Amsterdam: John Benjamins.

Eggins, Suzanne y James Martin (1997): Géneros y registros del discurso. En: Van Dijk, Teun (comp.), Estudios del discurso: introducción multidisciplinaria, vol.1, pp. 335-371. Barcelona 2000: Gedisa.

Fuentes Rodríguez, Catalina (1993): Un acercamiento a las unidades supraoracionales. Philologia hispalensis, 8, pp. 25-36.

Garnham, Alan; Oakhill, Jane y Philip Johnson-Laird (1982): Referential continuity and the coherence of discourse. En: Cognition, 11, pp. 29-46.

Garrido, Joaquín (1997): Estilo y texto en la lengua. Madrid: Gredos.

Garrido, Joaquín (2007): Construcción de discurso en noticias de prensa. En: Revista Española de Lingüística, 37, pp. 139-168. [http://www.sel.edu.es/pdf/ene-dic07/RSEL-37-Garrido.pdf] [30-10-2013]

Garrido, Joaquín (2009): Manual de lengua española. Madrid: Castalia.

Givón, Thomas (1983): Topic continuity in discourse: A quantivity cross-language study. Amsterdam: John Benjamins.

Givón, Thomas (1995): Coherence in text vs. coherence in mind. En: Givón y Gernsbacher (eds.), Coherence in Spontaneous Text, pp. 59-100. Amsterdam: John Benjamins.

Halliday, Michael y Ruqaiya Hasan (1976): Cohesion in English. Londres: Longman.

Hasan, Ruqaiya (1984): The nursery tales as a genre. Nottingham Linguistic Circular, 13, pp. 71-102.

Hidalgo Downing, Raquel (2003): La tematización en el español hablado. Madrid: Gredos.

Labov, William (1972): Language in the inner city. Studies in the Black English vernacular. Filadelfia: University of Pennsylvania Press.

Longacre, Robert (1979): The paragraph as a grammatical unit. En: Talmy Givón (ed.), Discourse and syntax. Syntax and Semantics, 12, pp. 115-134. Nueva York: 
Academic Press.

Longacre, Robert (1983): The Grammar of Discourse. Nueva York: Plenum Press.

Longacre, Robert (1992): Towards an Exegesis of 1 John Based on the Discourse Analysis of the Greek Text. En: David Alan Black (ed.), Linguistics and New Testament Interpretation: Essays on Discourse Analysis, pp. 271-286. Nashville: Broadman.

Mann, William y Sandra Thompson (1988): Rhetorical Structure Theory: Toward a Functional Theory of Text Organization. En: Text, 8 (3), pp.243-281.

Martín Zorraquino, María Antonia y José Portolés (1999): Los marcadores del discurso. En: Bosque, Ignacio y Violeta Demonte (dirs.), Gramática descriptiva de la lengua española, vol. 3, pp. 4051-4212. Madrid: Espasa Calpe.

O’Donnell, Mick (2008): Demonstration of the UAM CorpusTool for text and image annotation. En: Proceedings of the ACL-08: HLT Demo Session, pp. 13-16. Columbus, Ohio: Association for Computational Linguistics.

Paltridge, Brian (1994): Genre Analysis and the Identification of Textual Boundaries. En: Applied Linguistics, 15 (3), pp. 288-299.

Portolés, José (2004): Pragmática para hispanistas. Madrid: Síntesis.

Prince, E (1981): Toward a taxonomy of given-new information. En: Cole, Peter (ed.), Radical Pragmatics, pp. 223-255. Nueva York: Academic Press.

Reisigl, Martin (2008): Rhetoric of political speeches. En: Wodak, Ruth y Veronika Koller (eds.), The Handbook of Communication in the Public Sphere. Berlín: Mouton de Gruyter.

Renkema, Jan (2009): The texture of discourse: Towards an outline of connectivity theory. Amsterdam: John Benjamins.

Sanders, Ted; Schilperoord, Joost y Wilbert Spooren (eds.) (2001): Text Representation: Linguistic and Psycholinguistic aspects. Amsterdam: John Benjamins.

Schiffrin, Deborah (1994): Aproaches to discourse: Language as social interaction. Oxford: Blackwell.

Scott, Mike y Christopher Tribble (2006): Textual Patterns. Key words and corpus analysis in language education. Amsterdam: John Benjamins. 
Smith, Carlota (2003): Modes of discourse. The local structure of texts. Cambridge: Cambridge University Press.

Steen, Gerard (1999): Genres of discourse and the definition of literature. En: Discourse Processes, 28 (2), pp. 109-120.

Swales, John (1990): Genre analysis: English in academic and research settings. Cambridge: Cambridge University Press.

Thompson, Susan Elizabeth (2003): Text-structuring metadiscourse, intonation and the signalling of organisation in academic lectures. En: Journal of English for Academic Purposes, 2, pp. 5-20.

Upton Thomas y Ulla Connor (2009): An approach to corpus-based discourse analysis. The move analysis as example. En: Discourse Studies, 11, pp. 585-605.

van Dijk, Teun (1977): Text and Context: Exploration in the semantics and pragmatics of discourse. Londres: Longman.

van Dijk, Teun (1983): La Ciencia del Texto. Barcelona: Paidós. [Original en holandés de 1978]

van Dijk, Teun (1988): News as discourse. Hillsdale, Nueva Jersey: Lawrence Erlbaum. van Dijk, Teun (1999): Ideología: una aproximación multidisciplinaria. Barcelona Gedisa.

Vilches, Fernando; Sarmiento, Ramón; Albaladejo, Tomás; Urrutia, Hernán; Pinilla, Raquel y Santiago Fiorito (2007): Manual de Retórica Parlamentaria de la Asamblea de Madrid. Madrid: Asamblea de Madrid.

Werlich, Egon (1975): Typologie der Texte. Munich: Fink.

Wolf, Florian y Edward Gibson (2006): Coherence in natural language: Data Structures and Applications. Cambridge, Massachusetts: MIT Press.

Recibido:15 junio 2013

Aceptado: 15 septiembre 2013

Revisado: 30 octubre 3013

Publicado: 31 octubre 2013 